\title{
Mesoscale Eddies in the Open Ocean: Review of Experimental Investigations
}

\author{
M. N. Koshlyakov ${ }^{1,}$, V. N. Belokopytov ${ }^{2}$ \\ ${ }^{1}$ Shirshov Institute of Oceanology, Russian Academy of Sciences, Moscow, Russian Federation \\ ${ }^{2}$ Marine Hydrophysical Institut of RAS, Sevastopol, Russian Federation \\ 凶nkoshl@ocean.ru
}

The paper is aimed at reviewing the studies of mesoscale eddies in the open ocean carried out by the Soviet and foreign institutions during the experiments in the specified geographical regions.

The eddy-current effects are known since the 1930ies, and just the experiments "Polygon-67" in the Arabian Sea, "Polygon-70", MODE, POLYMODE, Tourbillon, "Mesopolygon" in the tropical Atlantic, "Megapolygon" in the northwestern Pacific Ocean have advanced our knowledge about physical nature of the ocean eddy dynamics. Long-term complex measurements including current meters at the moored buoy arrays accompanied by a series of hydrographic surveys have provided the required experimental data for developing the theory of mesoscale variability. It explained arising and evolution of the eddies in the ocean as a result of interaction between various physical processes: baroclinic instability of a large-scale current, transformation of geostrophic turbulence in the Rossby wave field, barotropization of eddies and others.

Later on, the studies of the ocean mesoscale variability evolved from the oceanographic surveys and special-purpose experiments at the polygons performed due to the research vessel cruises to the satellite altimetry methods and the drifter technologies. All the modern global estimates of eddy formations published in the last decade confirm the previous summaries, particularly those describing spatial distribution of the eddy kinetic energy in the World Ocean. They also represent new or the improved assessments of the eddies' various characteristics: their size, drift velocity and direction, sign of rotation, nonlinearity, trajectory shear and others.

Despite of the progress in remote sensing and regular launching of great amount of drifters and profiling floats, it is still difficult to obtain a comprehensive pattern of eddy dynamics within the whole World Ocean. It seems perspective to resume in future special-purpose experiments in the key regions of the World Ocean based on modern technologies.

Keywords: review, mesoscale eddies, Rossby waves, baroclinic instability, eddy barotropization, drifters, satellite altimetry

Acknowledgments: the work was carried out within the framework of the state task of IO RAS on theme No. 0149-2019-0004, MHI RAS on theme No. 0827-2018-0001.

For citation: Koshlyakov, M.N. and Belokopytov, V.N., 2020. Mesoscale Eddies in the Open Ocean: Review of Experimental Investigations. Physical Oceanography, [e-journal] 27(6), pp. 559-572. doi:10.22449/1573-160X-2020-6-559-572

DOI: 10.22449/1573-160X-2020-6-559-572

(C) M. N. Koshlyakov, V. N. Belokopytov, 2020

(C) Physical Oceanography, 2020

\section{Introduction}

The first evidence of the existence of eddies and meandering of the Gulf Stream and Kuroshio jet currents in the ocean appeared in the 1930s. [1-3]. Already at that time, both large eddy formations with the dimensions of up to $200 \mathrm{~km}$ in diameter, well distinguishable by water temperature, and small eddies (up to $20 \mathrm{~km}$ ), weakly expressed in the thermohaline structure of waters, were distinguished. In the 19501960s, synoptic hydrological surveys were carried out using several vessels (Operation Cabot [4]), radio navigation systems, bathythermographs, electromagnetic current meters, floats of neutral buoyancy began to be introduced into oceanographic practice, which, as a result, contributed to the widespread 
detection of eddies. Eddy structures began to be found not only in the Gulf Stream and Kuroshio regions [4-7], but also in the Gulf of Mexico [8], the zone of the East Australian Current [9, 10], as well as in other parts of the World Ocean. Nevertheless, the eddies were not yet perceived at that time as a universal phenomenon inherent in the entire World Ocean, they were not attributed to a separate class of oceanic movements. In contrast to atmospheric sciences, the theoretical foundations of dynamic processes in the mesoscale range for oceanology have not yet been developed.

\section{Experiments in 1960-1980s at polygons the in the ocean}

Purposeful experimental studies of mesoscale eddies in the ocean began in 1967 at the initiative of V.B. Shtokman in the Polygon-67 expedition of the Institute of Oceanology of the USSR Academy of Sciences in the Arabian Sea [11]. On the basis of two consecutive hydrological surveys, it was possible to identify unsteady undulating movements with a characteristic scale of about $100 \mathrm{~km}$ in the field of geostrophic currents [12].

Since the time interval of two months between the surveys in the Polygon-67 expedition did not allow tracing the evolution of eddy formations on the basis of their mutual identification, the question about developing a new, more complex, extended observation program arose. Sufficiently long-term direct measurements of currents, which would provide the estimation of the structure and dynamics of eddy disturbances of large-scale circulation in open ocean areas located far from powerful jet currents, were required. In 1970, under the scientific supervision of L.M. Brekhovskikh, in the Tropical Atlantic, in the region of the North Equatorial Current periphery (Fig. 1), the experiment Polygon-70 was carried out for 6 months by Soviet oceanologists [13]. The main part of the field measurements was carried out using a system of 17 autonomous buoy stations (ABS), installed according to the "cross" scheme (Fig. 2), with current recorders down to $1500 \mathrm{~m}$ depth at 10 horizons.

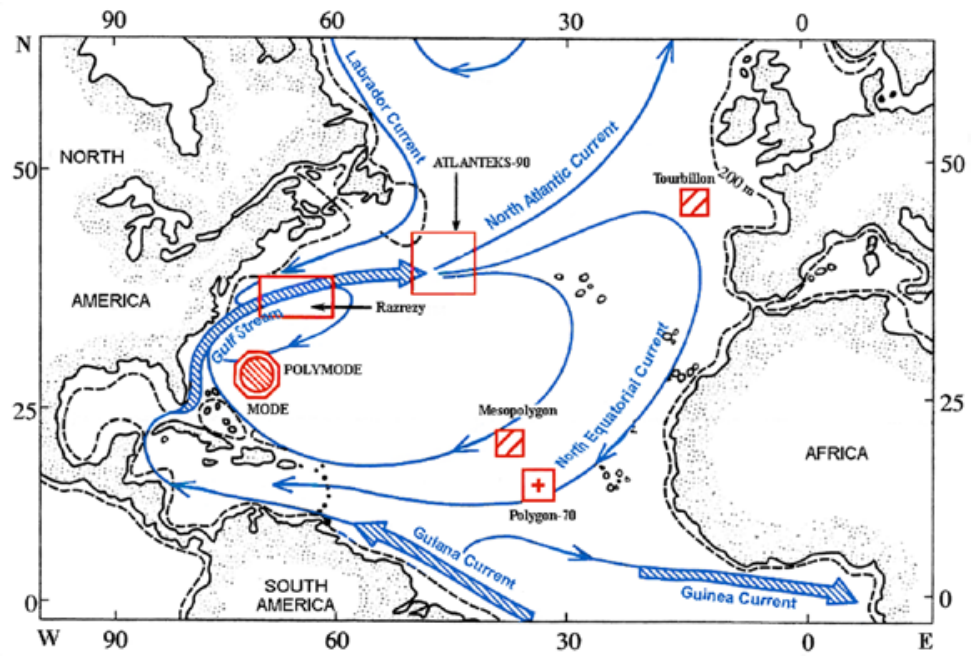

F i g. 1. Location of the experiments "Polygon-70”, MODE, POLYMODE, Tourbillon, "Razrezy", "Mesopolygon”, “ATLANTEKS-90” 


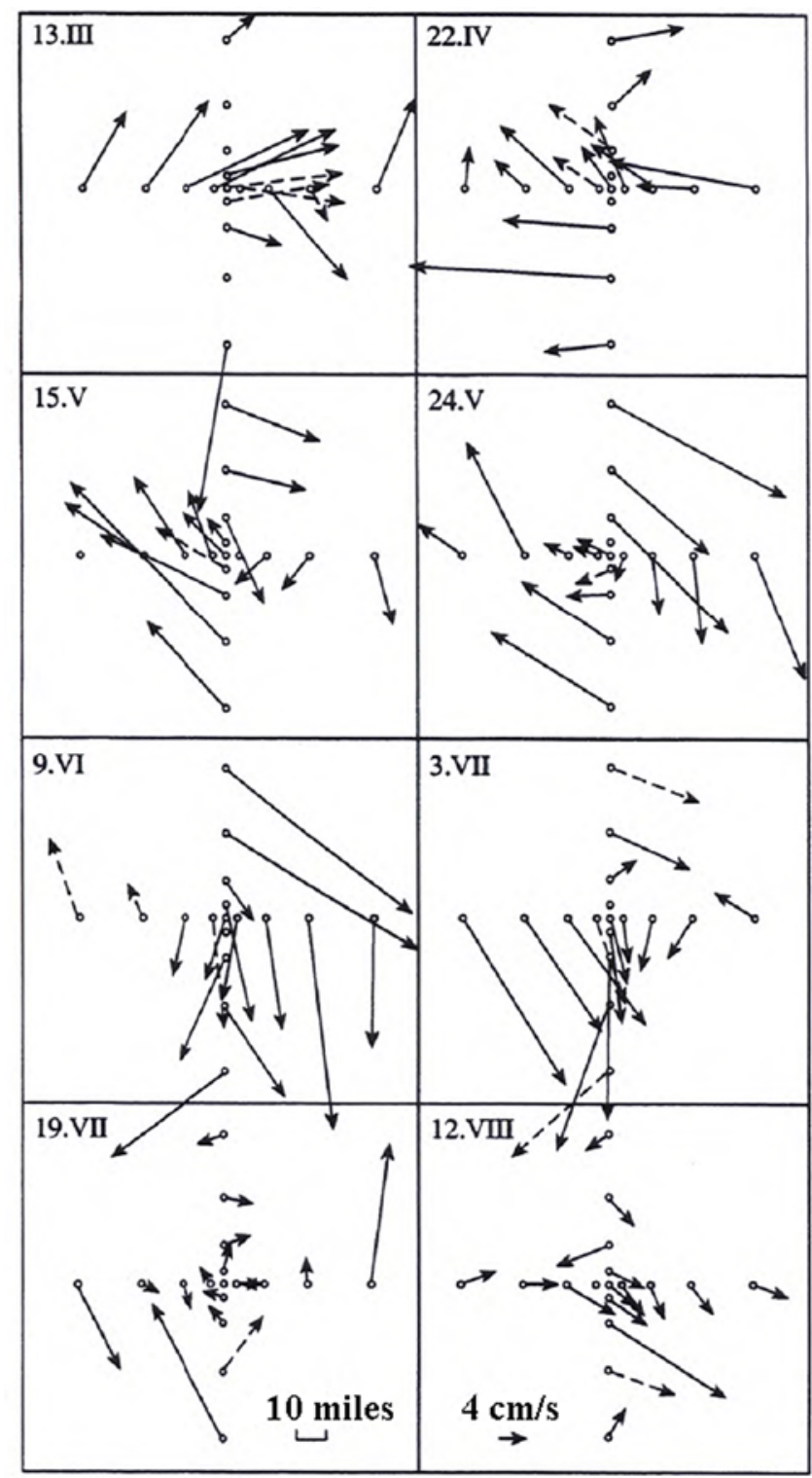

F i g. 2. Current vectors at $400 \mathrm{~m}$ horizon based on the data of the "Polygon-70" experiment

During the experiment we traced in detail the passage of a well-pronounced anticyclonic eddy [14] through the polygon water area in the period April - June 1970, which had an elliptical shape with a semi-minor axis of about $100 \mathrm{~km}$ and a semi-major axis of $200 \mathrm{~km}$ (Fig. 2). The vertical distribution of current velocity in the eddy had two maxima: the first in the surface layer, and the second in 400-500 m layer. The currents in these layers reached $45 \mathrm{~cm} / \mathrm{s}$ velocity, which was an order of magnitude higher than the velocities characteristic of the background North Passat Current. In addition to the main eddy, the peripheral parts of the neighboring eddies, which together constituted a "dense eddy packing”, were identified. The presence of such a dynamic structure later served as one of the substantiations of the wave PHYSICAL OCEANOGRAPHY VOL. 27 ISS. 6 (2020) 
interpretation of the experimental results. Despite the fact that the orbital velocity of eddies significantly predominates over the velocity of their translational motion [15-17], the theory of linear baroclinic Rossby waves made it possible to quite convincingly explain the observed relationship between the spatial and temporal scales of currents and to interpret the general direction of movement of eddies as a result of the combined action of $\beta$-effect and large-scale advection by the North Equatorial Current.

Polygon-70 was of great importance for oceanology, it stimulated the rapid growth of research on eddy motions in all oceans and seas. Eddies of this type, which were detected in this experiment, are called "synoptic eddies of the open ocean” in the domestic literature.

In 1973, American oceanographers carried out the Mid-Ocean Dynamics Experiment (MODE) project in the Sargasso Sea, southwest of Bermuda (Fig. 1). Despite the fact that it used a wider set of measuring instruments than in the Polygon-70, the main results of these experiments turned out to be close [18]. The characteristic time period of eddy motions in the ocean was about 100 days, the spatial scale was about $70 \mathrm{~km}$. The field of currents was mostly isotropic; its intensity increased when approaching the zones of large-scale currents action the Gulf Stream and the North Equatorial Current - and in the areas with increased dissection of the bottom.

In 1977-1979 in the MODE region (Fig. 1), the largest in the field of oceanology, the joint Soviet-American experiment POLYMODE (Polygon + $M O D E$ ) was carried out [19, 20]. Its integral part was the "Synoptic-dynamic experiment” (SDE), carried out under the scientific supervision of A. Monin in the area of the Gulf Stream recirculation cell. Compared with the Polygon-70, the system of 19 moorings in the SDE experiment had a smaller number of measurement horizons (100, 400, 700, $1400 \mathrm{~m})$, but a much greater spatial coverage (about $300 \mathrm{~km}$ ) and twice longer the duration of operation (13 months).

Throughout the POLYMODE, hydrological surveys were constantly carried out with various steps in space: from micro-polygons to the surveys of a large-scale structure (17 surveys). They were attended by vessels of Marine Hydrophysical Institute of the Academy of Sciences of the Ukrainian SSR (MHI), the Hydrographic Service of the Navy, the Institute of Oceanology of the Academy of Sciences of the USSR, Hydrometeorological Service, Acoustic Institute of the Academy of Sciences of the USSR. The largest volume of observations was carried out by MHI, where the program of hydrological surveys was developed, which was adopted as a single for all vessels of the interdepartmental expedition. The research vessels of the MHI "Akademik Vernadsky" and "Mikhail Lomonosov” carried out 9 large-scale surveys, 16 micro-range surveys, and 32 moorings installations [21-23].

In total, 22 eddies with almost equal repeatability of cyclonic and anticyclonic rotation, which moved across the polygon in a westerly direction at 2-10 cm/s velocity [24], were identified. The level of temporal variability of the mesoscale eddies energy (Fig. 3) was very significant [25]. The January - May 1978 period, when the passage of several powerful anticyclones separated by regions of weak cyclonic vorticity led to a sharp increase in the total kinetic energy of the currents, stood out especially. 


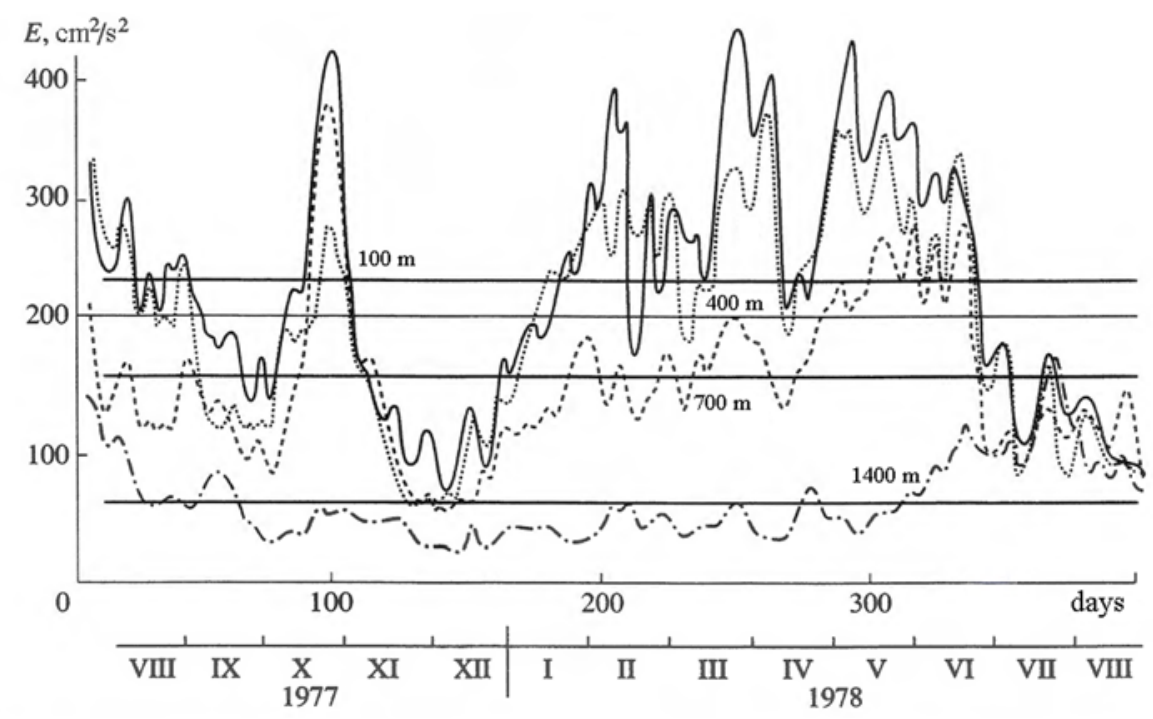

F i g. 3. Time-series of specific kinetic energy of mesoscale eddies averaged over all the measurements of the POLYMODE current meters moorings. Straight lines show the energy mean values at the depth levels

Subsequently, during numerous expeditionary studies, not only the above mentioned systems of interconnected eddies of different signs but also individual well-defined eddies were repeatedly recorded. Within the framework of the large domestic program "Razrezy" during oceanographic surveys of the Gulf Stream in 1984-1990 it was possible to trace various stages of the western boundary current interaction with the rings generated by it: detachments of meanders, their reverse absorption by the main stream, secondary separations, transformation of meanders into separate eddies, etc.

According to theoretical concepts [20], the main cause for the generation of mesoscale eddies is the baroclinic instability of large-scale currents. The formation of intense anticyclonic eddies POLYMODE in the period January - May 1978 was interpreted as a consequence of baroclinic instability of the Gulf Stream recirculation branch (countercurrent). This interpretation is supported by a number of the current field features: the spatial scale of anticyclones corresponds to the Rossby baroclinic scale; vertical shear of currents emphasizes the baroclinic structure of eddies; the anticyclonic vorticity of eddies correlates well with the anticyclonic meanders of the southern periphery of the Gulf Stream countercurrent; kinetic energy increases in the direction of the Gulf Stream countercurrent core; the relative displacement of perturbation centers of the pressure and density fields is located exactly in the direction that provides the maximum release of the available potential energy of the Gulf Stream countercurrent [26].

The evolution of the hydrophysical fields at the polygon confirmed the theoretical concepts [20] that with a decrease in the energy pumping (as it was in June 1978) the eddies are barotropized and their horizontal dimensions grow to 
the Rhines scale. As a result, a cyclical process, in which the periods of intense eddy formation associated with baroclinic instability of the main flow alternate with periods of transformation of geostrophic turbulence in the field of Rossby waves, arises. During such periods of transformation, there is a strong interaction between individual eddies and jets, as was observed in winter - spring 1978. Then, almost all eddies that passed through the polygon significantly changed their shape, size and intensity.

The results of POLYMODE, the largest of the experiments in this direction, significantly expanded our understanding of the physical processes of the formation and evolution of eddies in the open ocean and, in general, had a strong effect on further studies of mesoscale movements in the World Ocean.

At the end of 1979, during the completion of POLYMODE, in the northeastern Atlantic near the Bay of Biscay, the Franco-British experiment Tourbillon [27], comparable in terms of the volume of expeditionary work (10 ABS for 8 months) and the obtained results with the projects Polygon-70 and MODE, was launched. At the beginning of the work, an anticyclonic eddy with 50-70 km radius, which was traced to a depth of $4000 \mathrm{~m}$ and moved westward at an average velocity of $1.8 \mathrm{~cm} / \mathrm{s}$, was recorded. At the end of the experiment, a second, less intense cyclonic eddy approached the polygon.

In the second half of 1987, on the initiative of A. Monin, the Megapolygon experiment was carried out in the northwestern part of the Pacific Ocean in the area of the Subarctic front for 2.5 months. The very name of the experiment emphasizes its wide spatial coverage: 177 moorings were deployed at the nodes of a triangular grid with a step of $42.5 \mathrm{~km}$ at 120 and $1200 \mathrm{~m}$ horizons (on some moorings, additionally at 400 and $4500 \mathrm{~m}$ horizons). A significant contribution to the total amount of experimental material was the implementation of 6 hydrological surveys of the polygon within a relatively short time of the experiment.

Despite almost the half of the information lost due to the passage of typhoons, more than 20 mesoscale eddies were recorded [28-30]. One of the important results of the experiment was the discovery of significant differences in the structure of currents in the main thermocline (horizons 120 and $400 \mathrm{~m}$ ) and in deeper layers (1200 and $4500 \mathrm{~m})$ (Fig. 4). The current fields at 120 and $4500 \mathrm{~m}$ were almost uncorrelated with each other, while the dynamic structures at 1200 and $4500 \mathrm{~m}$ were generally similar. In the main thermocline, the horizontal scale of mesoscale eddies (35 km) was close to the baroclinic Rossby scale; in the depths of the ocean it corresponded to the Rhines scale $(80 \mathrm{~km})$, and it was in the deep layers where a stable westerly motion of eddies was observed.

As for the experiments Polygon-70 and POLYMODE, several physical processes were considered as the reasons for the spatial-temporal variability of the observed fields of the Megapolygon: the joint action of $\beta$-effect and capture by a large-scale current as the cause of the western transport of eddies; alternation of periods of eddy generation by baroclinic instability of the main stream and subsequent barotropization of eddies with an increase in their scale; origin and evolution of Rossby waves. 


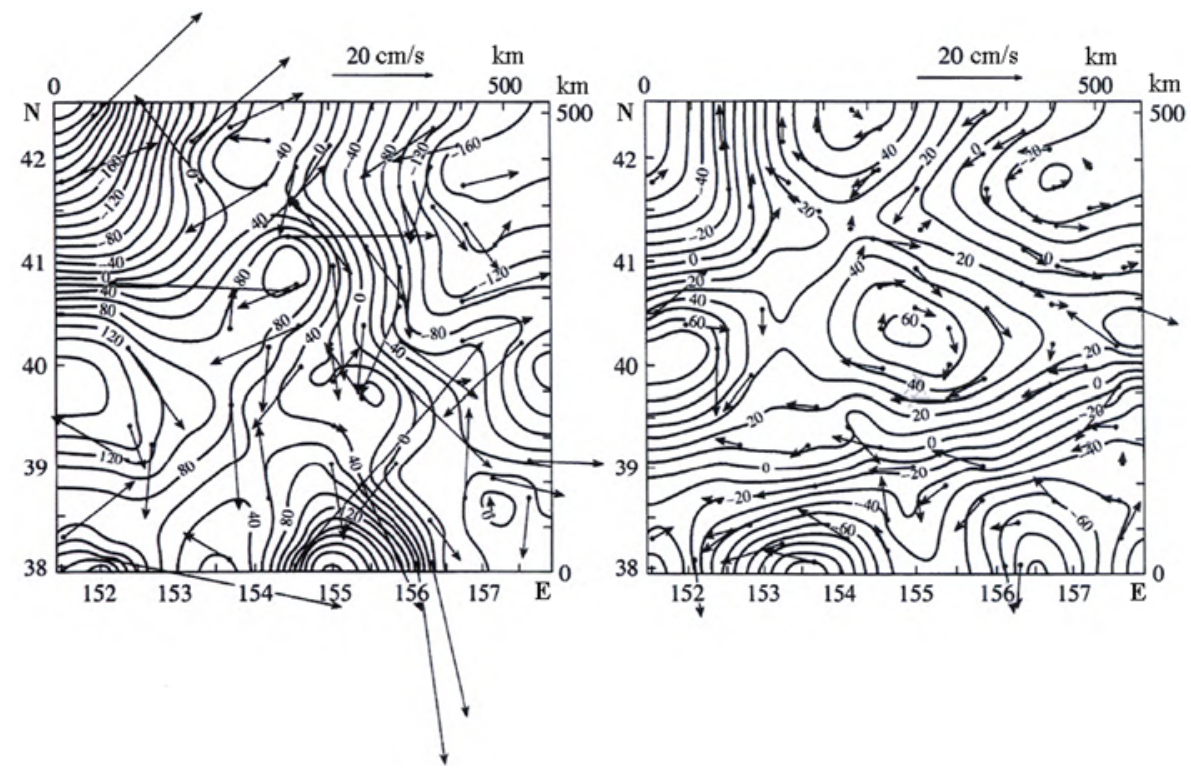

F i g. 4. Current vectors and stream function anomalies $\left(10^{6} \mathrm{~cm}^{2} / \mathrm{s}\right)$ at the depths $120 \mathrm{~m}$ (to the left) and $1200 \mathrm{~m}$ (to the right) in the region of the "Megapolygon" experiment on October 2, 1987

In 1985, during the Mesopolygon experiment in the Tropical Atlantic, the Institute of Oceanology of the USSR Academy of Sciences carried out a detailed study of the Mediterranean water eddy (meddy), which is a separate class of oceanic eddies, - a deep anticyclonic eddy [31]. Using a measuring system of 15 moorings and a series of hydrological surveys, the characteristics of the meddy, which lay in the 780-1400 m layer and had an ellipsoidal shape with axes of 70 and $55 \mathrm{~km}$, were determined. The maximum velocity in the eddy at a distance of $15 \mathrm{~km}$ from its center reached $30 \mathrm{~cm} / \mathrm{s}$ at a depth of $1000 \mathrm{~m}$. Large anomalies relative to the background values of temperature and salinity $\left(4.5{ }^{\circ} \mathrm{C}\right.$ and $0.87 \%$ ) and a significant distance $(2500 \mathrm{~km})$ from the formation place of meddies near the Iberian Peninsula have experimentally proved the stability and duration of the existence of such eddy formations, which contribute to the formation of intermediate water masses of the ocean.

\section{Development of eddy studying in the ocean}

The most known of the specialized experiments on the study of mesoscale eddies in the ocean at polygons were carried out in the 1970s - 1980s. The results achieved in them were generalized in many works, in particular, in [20,32, 33]. General estimates of eddy activity in the World Ocean, made in different years, were based on various types of measurements and calculations, which included: data on drift of vessels [34, 35], calculations of geostrophic currents [32], instrumental measurements of currents [36, 37], data on the drift of surface and deep drifters [38-42], analysis of the thermohaline structure of waters [20, 43-47], and satellite altimetry data [48-54].

With the development of technical means and under the conditions of a constant decline in expeditionary activities in the oceans and seas, the role of 
satellite and drifter technologies in the field of experimental ocean research gradually became predominant. The dramatically increased volume of information from these sources has stimulated a large number of works devoted to methods of detecting eddy formations, geographic distribution, and spatial-temporal variability of eddies. From the point of view of obtaining reliable estimates of mesoscale variability in the ocean, each type of data has its own advantages and disadvantages. For example, the currently most used satellite altimeter data have global coverage and are independent of the weather, which provides the coverage of the entire ocean area, including understudied areas (with the exception of icecovered areas). However, satellite information is directly related only to the surface layer of the ocean, and the degree of its representativeness for deeper layers requires special study. It should also be borne in mind that, despite the progress in the field of gravimetric measurements, the problems of determining the exact shape of the geoid and, accordingly, the absolute dynamic topography have not been fully resolved. There are limitations for estimating the velocity of currents in the ocean equatorial zone due to the uncertainty of geostrophic balance that takes place there. Automatic eddy detection algorithms (Okubo-Weiss, winding-angle, etc.) are based on different mathematical approaches, and search results can vary greatly. The eddies formed by the shear instability of large-scale currents will not manifest themselves in the ocean level surface.

Nevertheless, the general estimates of the eddy activity in the World Ocean, based on various sources of information, give a generally consistent picture, which does not essentially contradict the generalizations carried out 30-50 years ago. Starting with the first $[34,35]$ and ending with the last [52-54] generalizations of the global distribution of mesoscale movements energy, its direct dependence on the intensity of large-scale currents is noted. From the very beginning, the idea, formulated in due time by K. Wünsch [55, p. 373; 56, p. 65], according to which the bulk of the energy in the mesoscale range is concentrated near the western boundary currents, which serve as generators of eddy energy for the rest of the ocean, arose. The results of more than 20-year altimetric measurements and analysis of a huge number of drifter trajectories also confirm that the eddy energy (up to $4500 \mathrm{~cm}^{2} / \mathrm{s}^{2}$ ) is an order of magnitude higher than the average kinetic energy of average currents and is the maximum in the region of intense jet streams (Fig. 5).

If earlier it was believed that the most powerful energy sources for mesoscale movements are the Gulf Stream and Kuroshio, now the list of geographic regions with the highest intensity of eddy energy is as follows (in descending order): the Agulhas current recirculation area, the Kuroshio system, the Gulf Stream system, the area of the confluence of the Brazilian and Falkland Current, Antarctic Circumpolar Current (ACC), East Australian Current. The system of equatorial currents is distinguished by a sufficiently high level of eddy energy. It is confirmed that in the ACC, a significant increase in the energy of eddy motions is not due to an increase in the velocity of a large-scale flow, but as a result of abrupt changes in the bottom topography, as, for example, in the Drake Passage or over underwater ridges southward of New Zealand. As noted in earlier works, the bottom topography effect is much less pronounced in the Kuroshio - North Pacific Current 
system (near the Imperial Seamounts) and is very weakly noticeable in the Gulf Stream - North Atlantic Current system (when crossing the Mid-Atlantic Ridge).
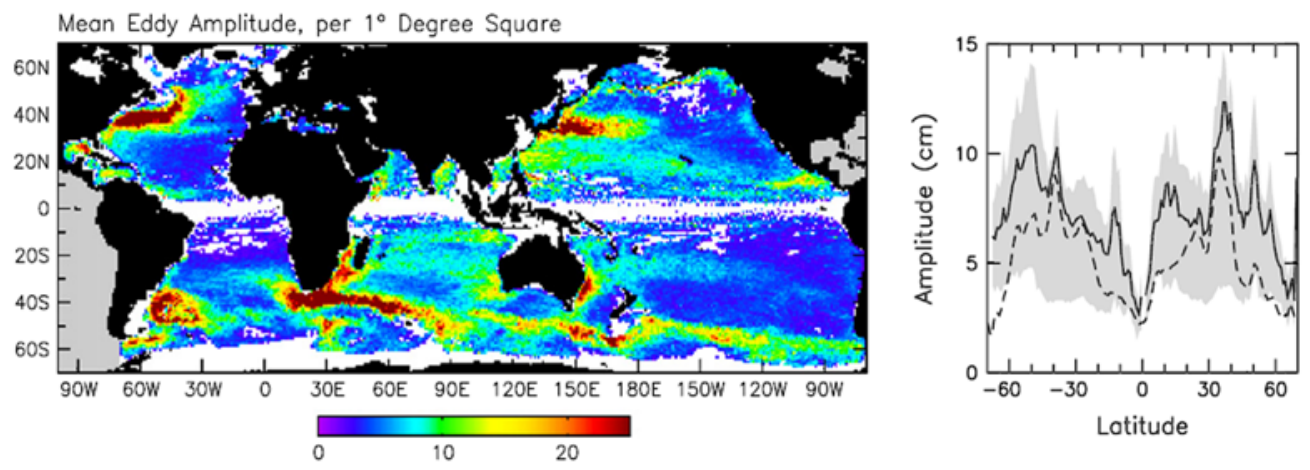

F i g. 5. Spatial (to the left) and meridional (to the right) distribution of the amplitude values (averaged at the $1^{\circ} \times 1^{\circ}$ grid) of the eddies whose lifetimes are $\geq 16$ weeks [53, Fig.10, p. 182]

Estimates of the horizontal dimensions of open ocean eddies based on measurements of the first generation of altimeters and hydrological data had a fairly wide scatter, on average grouping around the values of the local Rossby baroclinic scale [20, 33, 35, 57, 58]. According to the data of the modern generation of satellite altimeters $[50,52,53]$, the eddy radii in more than $90 \%$ of cases are within the range of 50-150 km, and no significant differences between the sizes of cyclones and anticyclones have been revealed. The size of the eddies decreases monotonically from about $200 \mathrm{~km}$ in the near-equatorial regions to $75 \mathrm{~km}$ at $60^{\circ}$ latitude, i.e. the decrease in the size of the eddies occurs much more slowly than follows from the decrease in the Rossby baroclinic radius with latitude. This discrepancy is explained in [59] by the effect of a nonlinear cascade of kinetic energy transfer over the spectrum.

Traditionally, the literature discusses the question of the direction of eddy motion [20, 32, 60-62]. In the works of the last ten years [52-54, 63] it is stated that eddies move mainly in the western direction (75 \% of all cases), except for the regions of the predominant eastern transport: the Gulf Stream, Kuroshio, ACC. Taking into account the discussion that took place in the literature on the significant excess of the movement velocity of the ocean surface anomalies in comparison with the theoretical velocity of linear Rossby waves, the work [53] should be highlighted. Noting that the estimates of the displacement of disturbances in the ocean level surface largely depend on the spatial resolution of the data and methods of their smoothing, the authors argue that the velocities of eddies are nevertheless close to the phase velocity of long baroclinic Rossby waves. In [54], on the basis of the relation between the zonal phase velocity of Rossby waves $C_{\mathrm{R}}$ and the scale of the velocity of eddy motions $u_{\mathrm{t}}$, the different physical nature of the western transport of mesoscale disturbances in the tropics and in the middle latitudes is explained. In the tropics, where $u_{\mathrm{t}}<\left|C_{\mathrm{R}}\right|$, nonlinear interactions lead to the transfer of energy from eddies formed by baroclinic instability to Rossby waves, further strengthening them. At higher latitudes, where $u_{\mathrm{t}}>\left|C_{\mathrm{R}}\right|$, this process is no longer dominant due to a decrease in wave scales. PHYSICAL OCEANOGRAPHY VOL. 27 ISS. 6 (2020) 
The geographic boundary between the two dynamic regimes $\left(u_{\mathrm{t}} \sim\left|C_{\mathrm{R}}\right|\right)$ runs along $\pm 30^{\circ}$ latitude (Fig. 6), which generally corresponds to the estimate of the transition boundary from Rossby waves to nonlinear eddies obtained in [52].

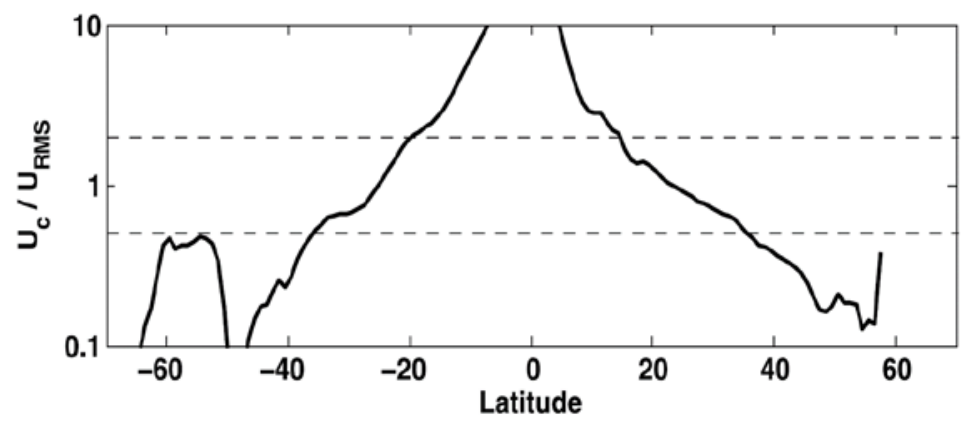

F i g. 6. Ratio of the Rossby waves zonal phase velocity $C_{R}$ to the eddy velocity scale $u_{t}$ of the of the first baroclinic mode [54, Fig. 10, p. 9]. Dashed lines show the levels of $C_{\mathrm{R}} / u_{\mathrm{t}}$ equal to $1 / 2$ and 2

The methods for combining multiple satellite datasets, applied from the 1990s, provide additional opportunities for ocean eddy dynamics studies. A number of interesting results were obtained in [52, 53]: the prevalence (outside the tropical zone) of eddies with strong nonlinearity (the maximum linear rotation velocity is more than 5 times higher than the movement velocity); a slight predominance of anticyclones over cyclones in the Northern Hemisphere; increased frequency of cyclones among the most intense eddies in the Southern Hemisphere; a slow shift of eddy trajectories towards the poles for the cyclones and towards the equator for the anticyclones.

\section{Research perspectives}

Despite the significant advances in Earth remote sensing methods, it is still not possible to obtain a complete, comprehensive understanding of mesoscale eddies for the entire ocean volume from experimental data. The launch of a large number of drifters and Argo profiling floats cannot fully compensate for the reduction in dedicated oceanographic surveys and polygon measurements. This is due both to the stochasticity and unpredictability of the trajectories of the drifting objects, and to the restrictions on the sounding depth that exist for them. Promising methods and tools for experimental studies of eddy dynamics in the ocean can be considered: new panoramic altimeters with increased spatial resolution; new high resolution geoid models; new autonomous sounding instruments operating for a long time according to the given programs; new means of remote measurement of salinity with increased accuracy; a new generation of moorings for the renewal of field polygon experiments in key areas of the World Ocean.

\section{REFERENCES}

1. Iselin, C.O'D., 1936. A Study of the Circulation of the Western North Atlantic. Papers in Physical Oceanography and Meteorology, 4(4), 101 p. doi:10.1575/1912/1087

2. Church, P.E., 1937. Temperature of the Western North Atlantic from Thermograph Records. Publications Scientifiques, 4, 32 p. 
3. Uda, M., 1935. On the Distribution, Formation and Movement of the Dicho-Thermal Water to the Northeast of Japan. Uni to Sora, 15, pp. 445-452 (in Japanese).

4. Iselin, C.O'D and Fuglister, F.C., 1948. Some Recent Developments in the Study of the Gulf Stream. Journal of Marine Research, 7(3), pp. 317-329.

5. Fuglister, F.C. and Worthington, L.V., 1951. Some Results of a Multiple Ship Survey of the Gulf Stream. Tellus, 3(1), pp. 1-14. https://doi.org/10.3402/tellusa.v3i1.8614

6. Kitano, K., 1975. Some Properties of the Warm Eddies Generated in the Confluence Zone of the Kuroshio and Oyashio Currents. Journal of Physical Oceanography, 5(2), pp. 245-252. doi:10.1175/1520-0485(1975)005<0245:SPOTWE >2.0.CO;2

7. Swallow, J.C., 1971. A Discussion on Ocean Currents and Their Dynamics - The Aries Current Measurements in the Western North Atlantic. Philosophical Transactions of the Royal Society. Series A. Mathematical, Physical and Engineering Sciences, 270(1206), pp. 451-460. https://doi.org/10.1098/rsta.1971.0084

8. Leipper, D.F., 1970. A Sequence of Current Patterns in the Gulf of Mexico. Journal of Geophysical Research: Oceans and Atmospheres, 75(3), pp. 637-657. doi:10.1029/JC075i003p00637

9. Hamon, B.V., 1965. The East Australian Current, 1960-1964. Deep-Sea Research and Oceanographic Abstracts, 12(6), pp. 899-921. doi:10.1016/0011-7471(65)90813-2

10. Boland, F.M. and Hamon, B.V., 1970. The East Australian Current, 1965-1968. Deep Sea Research and Oceanographic Abstracts, 17(4), pp. 777-794. doi:10.1016/0011-7471(70)90041-0

11. Stockman, W.B., Koshlyakov, M.N., Ozmidov, R.V., Fomin, L.N. and Yampolsky, A.D., 1969. Long-Term Measurements of the Physical Field Variability on Oceanic Polygons, as a New Stage in the Ocean Research. Doklady Akademii Nauk SSSR, 186(5), pp. 1070-1073 (in Russian).

12. Koshlyakov, M.N., Galerkin, L.I. and Tru’ong Dinh Hiê'n, 1970. On Mesostructure of Geostrophic Currents in the Open Ocean. Oceanology, 10(5), pp. 805-814.

13. Brekhovskikh, L.M., Fedorov, K.N., Fomin, L.M., Koshlyakov, M.N. and Yampolsky, A.D., 1971. Large-Scale Multi-Buoy Experiment in the Tropical Atlantic. Deep-Sea Research and Oceanographic Abstracts, 18(12), pp. 1189-1206. doi:10.1016/0011-7471(71)90026-X

14. Koshlyakov, M.N. and Grachev, Yu.M., 1974. [Medium-Scale Currents at the Hydrophysical Testing Polygon in the Tropical Atlantic]. In: V. G. Kort and V. S. Samoylenko, Eds., 1974. [Atlantic Hydrophysical Testing Polygon-70]. Moscow: Nauka, pp. 163-180 (in Russian).

15. Koshlyakov, M.N., 1973. Results Obtained at the Atlantic Polygon in 1970 in the Light of Some Theoretical Models of Free Rossby Waves. Oceanology, 13(5), pp. 760-767 (in Russian).

16. McWilliams, J.C. and Robinson, A.R., 1974. A Wave Analysis of the Polygon Array in the Tropical Atlantic. Deep-Sea Research and Oceanographic Abstracts, 21(5), pp. 359-368. doi:10.1016/0011-7471(74)90040-0

17. Konyaev, K.V. and Sabinin, K.D., 1981. Spectral Description of Synoptical Variability of Currents in the Ocean on Base of Polygon-70 and POLYMODE Data. Izvestiya of Academy of Sciences, USSR. Atmospheric and Oceanic Physics, 17(11), pp. 1191-1200.

18. The Mode Group, 1978. The Mid-Ocean Dynamics Experiment. Deep-Sea Research, 25(10), pp. 859-910. doi:10.1016/0146-6291(78)90632-X

19. Robinson, A.R., 1982. Dynamics of Ocean Currents and Circulation: Results of POLYMODE and Related Investigations. In: A. Osborne and P. M. Rizzoli, Eds., 1982. Topics in Ocean Physics. New York: Esevier, pp. 3-29.

20. Kamenkovich, V.M., Koshlyakov, M.N. and Monin, A.S., 1986. Synoptical Eddies in the Ocean. Dordrecht: Springer, 376 p. https://doi.org/10.1007/978-94-009-4502-9

21. Nelepo, B.A., Bulgakov, N.P., Timchenko, I.E., Korotaev, G.K., Aretinskiy, G.Yu., Babiy, M.V., Ganson, P.P., Golubev, Yu.N., Grishin, G.A. [et al.], 1980. [Synoptic Eddies in the Ocean]. Kiev: Naukova dumka, 288 p. (in Russian). 
22. MHI, 1978. [Experimental Studies under the International Program "POLIMODE" (results of the 16th cruise of R/V Akademik Vernadsky)]. Sevastopol: MHI, 149 p. (in Russian).

23. MHI, 1978. [Experimental Studies under the International Program "POLIMODE" (results of the 17th cruise of $R / V$ Akademik Vernadsky and the 33rd cruise of $R / V$ Mikhail Lomonosov)]. Sevastopol: MHI, 178 p. (in Russian).

24. Kort, V.G., Pavlova, Yu.V. and Fomin, L.M., 1980. [Topography of the $15^{\circ} \mathrm{C}$ Isothermal Surface]. In: IO AS USSR, 1980. Izvestiya POLIMODE. Moscow: Institut Okeanologii AN SSSR. Issue 2, pp. 5-13 (in Russian).

25. Koshlyakov, M.N., Grachev, Yu.M., Mikhailichenko, Yu.G., Sazhina, T.G. and Yaremchuk, M.I., 1984. Generation of Synoptic Ocean Eddies in the POLYMODE Area. Oceanology, 24(1), pp. 5-14 (in Russian).

26. Grachev, Yu.M., Koshlyakov, M.N. and Mikhaylichenko, Yu.G., 1988. [Synoptic Eddies in the Sargasso Sea]. Moscow: Nauka, 220 p. (in Russian).

27. Le Groupe Tourbillon, 1983. The Tourbillon Experiment: a Study of a Mesoscale Eddy in the Eastern North Atlantic. Deep-Sea Research. Part A. Oceanographic Research Papers, 30(5), pp. 475-511. doi:10.1016/0198-0149(83)90086-9

28. Bubnov, V.A., Ivanov, Iu.A., Koshliakov, M.N., Kort, V.G., Monin, A.S. and Ovchinnikov, I.M., 1988. On Oceanic Eddies on the Megapolygon. Doklady Akademii Nauk SSSR, 301(6), pp. 1468-1471 (in Russian).

29. Koshlyakov, M.N., Maksimenko, N.A., Panteleev, G.G., Sazhina, T.G. and Yaremchic, M.I., 1992. Structure and Variability of the Velocity Field in the Ocean Depths Studied by Direct Current Measurements of "Megapolygon-87". In: Yu. A. Ivanov, ed., 1992. [Experiment Megapolygon]. Moscow: Nauka, pp. 251-259 (in Russian).

30. Maximenko, N.A., Koshlyakov, M.N., Ivanov, Y.A., Yaremchuk, M.I. and Panteleev, G.G., 2001. Hydrophysical Experiment "Megapolygon-87" in the Northwestern Pacific Subarctic Frontal Zone. Journal of Geophysical Research: Oceans, 106(C7), pp. 14143-14163. doi:10.1029/2000JC000436

31. Ivanov, Iu.A., Kort, V.G., Monin, A.S., Ovchinnikov, I.M. and Shadrin, I.F., 1986. On the Mesoscale Inhomogeneities of the Ocean. Doklady Akademii Nauk SSSR, 289(3), pp. 706-709 (in Russian).

32. Robison, A.R., ed., 1983. Eddies in Marine Science. Berlin, Heidelberg: Springer, 609 p. doi:10.1007/978-3-642-69003-7

33. Blatov, A.S. and Tuzhillin, V.S., 1990. [Mediumscale Eddies and Synoptic Variability in the World Ocean. Okeanologiya, vol. 8]. Moscow: VINITI AN SSSR, 248 p.

34. Wyrtki, K., Magaard, L. and Hager, J., 1976. Eddy Energy in the Oceans. Journal of Geophysical Research: Oceans and Atmospheres, 81(15), pp. 2641-2646. doi:10.1029/JC081i015p02641

35. Dantzler Jr., H.L., 1976. Geographic Variations in Intensity of the North Atlantic and North Pacific Oceanic Eddy Fields. Deep-Sea Research and Oceanographic Abstracts, 23(9), pp. 783-794. doi:10.1016/0011-7471(76)90846-9

36. Dickson, R.R., 1983. Global Summaries and Intercomparisons: Flow Statistics from LongTerm Current Meter Moorings. In: A. R. Robinson, ed., 1983. Eddies in Marine Science. Topics in Atmospheric and Oceanographic Sciences. Berlin, Heidelberg: Springer, pp. 278353. https://doi.org/10.1007/978-3-642-69003-7_15

37. Schmitz Jr., W.J. and Luyten, J.R., 1991. Spectral Time Scales for Mid-Latitude Eddies. Journal of Marine Research, 49(1), pp. 75-107. doi:10.1357/002224091784968585

38. Richardson, P.L., 1983. Eddy Kinetic Energy in the North Atlantic from Surface Drifters. Journal of Geophysical Research: Oceans, 88(C7), pp. 4355-4367. doi:10.1029/JC088iC07p04355

39. Krauss, W. and Käse, R.H., 1984. Mean Circulation and Eddy Kinetic Energy in the Eastern North Atlantic. Journal of Geophysical Research: Oceans, 89(C3), pp. 3407-3415. doi:10.1029/JC089iC03p03407 
40. Rossby, H.T., Riser, S.C. and Mariano, A.J., 1983. The Western North Atlantic - A Lagrangian Viewpoint. In: A. R. Robinson, ed., 1983. Eddies in Marine Science. Topics in Atmospheric and Oceanographic Sciences. Berlin, Heidelberg: Springer, pp. 66-91. doi:10.1007/978-3-64269003-7_4

41. Maximenko, N., Niiler, P., Centurioni, L., Rio, M.-H., Melnichenko, O., Chambers, D., Zlotnicki, V. and Galperin, B., 2009. Mean Dynamic Topography of the Ocean Derived from Satellite and Drifting Buoy Data Using Three Different Techniques. Journal of Atmospheric and Oceanic Technology, 26(9), pp. 1910-1919. https://doi.org/10.1175/2009JTECHO672.1

42. Lumpkin, R. and Johnson, G.C., 2013. Global Ocean Surface Velocities from Drifters: Mean, Variance, El Niño-Southern Oscillation Response, and Seasonal Cycle. Journal of Geophysical Research: Oceans, 118(6), pp. 2992-3006. doi:10.1002/jgrc.20210

43. Dantzler Jr., H.L., 1977. Potential Energy Maxima in the Tropical and Subtropical North Atlantic. Journal of Physical Oceanography, 7(4), pp. 512-519. doi:10.1175/15200485(1977)007<0512:PEMITT>2.0.CO;2

44. Levitus, S., 1982. Climatological Atlas of the World Ocean. NOAA/ERL GFDL Professional Paper 13. Princeton, N.J., 173 pp. (NTIS PB83-184093).

45. Emery, W.J., 1983. Global Summary: Review of Eddy Phenomena as Expressed in Temperature Measurements. In: A. R. Robinson, ed., 1983. Eddies in Marine Science. Topics in Atmospheric and Oceanographic Sciences. Berlin, Heidelberg: Springer, pp. 354-375. doi:10.1007/978-3-642-69003-7_16

46. Emery, W.J., Lee, W.G. and Magaard, L., 1984. Geographic and Seasonal Distributions of BruntVäisälä Frequency and Rossby Radii in the North Pacific and North Atlantic. Journal of Physical Oceanography, 14(2), pp. 294-317. doi:10.1175/1520-0485(1984)014<0294:GASDOB>2.0.CO;2

47. Chelton, D.B., deSzoeke, R.A., Schlax, M.G., El Naggar, K. and Siwertz, N., 1998. Geographical Variability of the First Baroclinic Rossby Radius of Deformation. Journal of Physical Oceanography, 28(3), pp. 433-460. doi:10.1175/15200485(1998)028<0433:GVOTFB>2.0.CO;2

48. Cheney, R.E., Marsh, J.G. and Beckley, B.D., 1983. Global Mesoscale Variability from Collinear Tracks of SEASAT Altimeter Data. Journal of Geophysical Research: Oceans, 88(C7), pp. 4343-4354. https://doi.org/10.1029/JC088iC07p04343

49. Shum, C.K., Werner, R.A., Sandwell, D.T., Zhang, B.H., Nerem, R.S. and Tapley, B.D., 1990. Variations of Global Mesoscale Eddy Energy Observed from Geosat. Journal of Geophysical Research: Oceans, 95(C10), pp. 17865-17876. doi:10.1029/JC095iC10p17865

50. Stammer, D., 1997. Global Characteristics of Ocean Variability Estimated from Regional TOPEX/POSEIDON Altimeter Measurements. Journal of Physical Oceanography, 27(8), pp. 1743-1769. doi:10.1175/1520-0485(1997)027<1743:GCOOVE>2.0.CO;2

51. Ducet, N., Le Traon, P.Y. and Reverdin, G., 2000. Global High Ocean Circulation from TOPEX/Poseidon and ERS -Joandal- of Geophysical Research: Oceans, 105(C8), pp. 19477-19498. doi:10.1029/2000JC900063

52. Chelton, D.B., Schlax, M.G., Samelson, R.M. and de Szoeke, R.A., 2007. Global Observations of Large Oceanic Eddies. Geophysical Research Letters, 34(15), L15606. doi:10.1029/2007GL030812

53. Chelton, D.B., Schlax, M.G. and Samelson, R.M., 2011. Global Observations of Nonlinear Mesoscale Eddies. Progress in Oceanography, 91(2), pp. 167-216. doi:10.1016/j.pocean.2011.01.002

54. Tulloch, R., Marshall, J. and Smith, K.S., 2009. Interpretation of the Propagation of Surface Altimetric Observations in Terms of Planetary Waves and Geostrophic Turbulence. Journal of Geophysical Research: Oceans, 114(C2), C02005. doi:10.1029/2008JC005055

55. Wunsch, C., 1981. Low Frequency Variability of the Sea. In: B. A. Warren and C. Wunsch, eds., 1981. Evolution of Physical Oceanography: Scientific Surveys in Honor of Henry Stommel. Cambridge: The MIT Press, pp. 342-374.

56. Wunsch, C., 1983. Western North Atlantic Interior. In: A. R. Robinson, ed., 1983. Eddies in Marine Science. Topics in Atmospheric and Oceanographic Sciences. Berlin, Heidelberg: Springer, pp. 46-65. doi:10.1007/978-3-642-69003-7_3 
57. Bernstein, R.L. and White, W.B., 1974. Time and Length Scales of Baroclinic Eddies in the Central North Pacific Ocean. Journal of Physical Oceanography, 4(4), pp. 613-624. doi:10.1175/1520-0485(1974)004<0613:TALSOB >2.0.CO;2

58. Fu, L.-L., 1983. On the Wave Number Spectrum of Oceanic Mesoscale Variability Observed by the SEASAT Altimeter. Journal of Geophysical Research: Oceans, 88(C7), pp. 43314341. doi:10.1029/JC088iC07p04331

59. Scott, R.B. and Wang, F., 2005. Direct Evidence of an Oceanic Inverse Kinetic Energy Cascade from Satellite Altimetry. Journal of Physical Oceanography, 35(9), pp. 1650-1666. doi:10.1175/JPO2771.1

60. Cushman-Roisin, B., Tang, B. and Chassignet, E.P., 1990. Westward Motion of Mesoscale Eddies. Journal of Physical Oceanography, 20(5), pp. 758-768. doi:10.1175/15200485(1990)020<0758:WMOME>2.0.CO;2

61. Chelton, D.B. and Schlax, M.G., 1996. Global Observations of Oceanic Rossby Waves. Science, 272(5259), pp. 234-238. doi:10.1126/science.272.5259.234

62. Killworth, P.D., Chelton, D.B. and De Szoeke, R.A., 1997. The Speed of Observed and Theoretical Long Extratropical Planetary Waves. Journal of Physical Oceanography, 27(9), pp. 1946-1966. doi:10.1175/1520-0485(1997)027<1946:TSOOAT>2.0.CO;2

63. Fu, L.-L., 2009. Pattern and Velocity of Propagation of the Global Ocean Eddy Variability. Journal of Geophysical Research: Oceans, 114(C11), C11017. doi:10.1029/2009JC005349

About the authors:

Mikhail N. Koshlyakov, Chief Research Associate, Laboratory of sea currents, Shirshov Institute of Oceanology (36, Nakhimov ave, 117997, Moscow, Russian Federation), Dr. Sci. (Phys.-Math.), professor, mnkoshl@ocean.ru

Vladimir N. Belokopytov, Leading Research Associate, Marine Hydrophysical Institut of RAS (2, Kapitanskaya str., 299011, Sevastopol, Russian Federation), Dr. Sci. (Geogr.), ORCID ID: 00000003-4699-9588, Scopus Author ID: 6602381894, v.belokopytov@gmail.com

Contribution of the co-authors:

Mikhail N. Koshlyakov - general scientific supervision of the research, preparation of the initial version of the text, critical analysis and revision of the text

Vladimir N. Belokopytov - analysis of materials on the research theme, review of literature on the research problem, preparation of the article text

All the authors have read and approved the final manuscript.

The authors declare that they have no conflict of interest. 